A radial steal syndrome occurs with all internal arteriovenous fistulae in the forearm where a side-to-side anastomosis has been performed, ${ }^{12-15}$ and Bussell et al. ${ }^{15}$ found associated symptoms in six out of seven patients investigated. Embolic phenomena also may occur. ${ }^{16}$ Ischaemic symptoms associated with fistulae in the cubital fossa were found in six of our 11 patients: paraesthesiae in the hand and forearm, claudication, and rest pain in the hand and less commonly in the forearm. An appreciable funotional loss occurred in only one patient who developed a florid steal syndrome, and she partially recovered after three months. The remaining 10 patients had no appreciable functional loss in the hand or forearm and regarded their symptoms as a minor inconvenience which in most cases only occurred during dialysis. In cases 4 and 10 a dramatic improvement in symptoms and signs occurred when a venous aneurysm developed at the site of the anastomosis.

End-to-side anastomosis at the wrist prevents the steal syndrome in the hand. Abbott et al., however, described a $55 \%$ early failure rate with end-to-side anastomoses at the wrist. ${ }^{17}$ Inadequate veins in the forearm have been one of the most frequent indications for performing an antecubital fistula operation and it is unlikely that good dilatation of these veins will be achieved at least for some months. Since there may be no forearm system sufficiently patent to maintain retrograde flow against the valve system in poor veins such as these, it is probably wise to perform a side-to-side anastomosis. It has proved possible to insert needles either at the antecubital fossa or into the cephalic or basilic veins of the upper arm, which dilate more rapidly. Only three of our patients were able to insert their own needles though several others were previously able to insert needles into the forearm system with a functioning fistula at the wrist. The re- latively high flow after antecubital fistulae and the good dilatation of the vein at the anastomosis seems to confer a greater resistance to thrombosis after traumatic needling and we have not found this to be a problem though two patients developed aneurysmal dilatation of the vein at the fistula. Single needle dialysis systems would probably solve many of these problems.

All the fistulae gave good arterial flows of at least $200 \mathrm{ml} /$ min during dialysis through 14-gauge thin-walled needles. There were no cardiovascular complications attributable to the size of the shunt even in patients with overt hypertensive and ischaemic heart disease.

\section{References}

1 Brescia, M. J., et al., New England fournal of Medicine, 1966, 275, 1089. 2 Cohen, S., et al., Transactions of the American Society for Artifical Internal Organs, 1968, 14, 421.

3 Vellar, I. D. A., Heale, W. F., and Doyle, J. C., Medical fournal of Australia, $1969,1,1279$.

- Konnak, J. W., Haig, O. G., and Easterling, R. E., Dialysis and Transplantation, 1973, 2, 17.

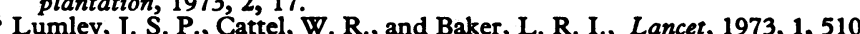

- Lumley, J. S. P., Cattel, W. R., and Baker,

7 Alvarez, J. J., et al., Surgery, 1970, 67, 355.

7 Alvarez, J. J., et al., Surgery, 1970, 67, 355 . 1969, 39, 259.
19. 1 . A., and Zerbino, V., Surgery, 1972, 2, 260.

10 Tice, D. A., and Zerbino, V., Surgery, 1972, 2, 260.

10 Hashmonai, M., et al., British fournal of $S$

12 Hurwich, B. J., American Fournal of Roentgenology, Radium Therapy, and Nuclear Medicine, 1968, 104, 394.

13 Hurwich, B. J., Nephron, 1968, 6, 673.

15 Bussell, J. A., Abbott, J. A., and Lim, R. C., Annals of Internal Medicine, $1971,75,387$.

16 Storey, B. G., et al., Surgery, 1969, 66, 325

17 Abbot, J, A., et al., Kidney International, 1973, 3, 342.

\title{
Across the Atlantic
}

\section{Role of Semen Cryobanking in American Medicine}

\author{
MARK S. FRANKEL
}

British Medical fournal, 1974, 3, 619-621

\begin{abstract}
Summary
In the United States there is little public policy regulating the activities of semen cryobanks. The medical profession has also been conspicuously silent on this aspect of medical practice. The potential benefits of semen cryobanking are enormous, yet like all other technologies its application (particularly commercially) may produce unexpected and unwanted consequences. It is suggested that a co-operative effort is needed between public officials and the medical profession to establish standards and guidelines which would maximize the benefits of this technique.
\end{abstract}

\footnotetext{
Program of Policy Studies in Science and Technology, George Washington University, Washington, D.C., 20006, U.S.A.

MARK S. FRANKEL, B.A., Research Associate
}

\section{Introduction}

In recent years the number of semen cryobanks in the United States has increased rapidly. Though the concept of semen cryobanking - the freezing and preservation of semen at low temperatures-can be traced back to $1866^{1}$ its implementation on a practical and commercial basis is more recent. In 1969 there were fewer than 10 such banks in the country; by the end of 1973 there were 16, including three major commercial banks with a combined total of seven branch offices. This rapid increase can be attributed to two reasons. Firstly, with the heightened popularity of vasectomy many men have sought a type of "fertility insurance" by freezing their semen for possible later use. Secondly, there has been an increased demand by infertile couples, representing about $30 \%$ of all marriages in the United States, for artificial insemination. In the case of a husband's infertility, which accounts for $40-50 \%$ of infertility among American married couples, a donor's semen may be used for insemination independent of time and place.

The most common technique for freezing and storing semen is immersion in liquid nitrogen at $-196.5^{\circ} \mathrm{C} .^{2} \mathrm{~s}$ Though the fertilizing capacity of frozen semen has generally been found to 
be about two-thirds of that expected with fresh semen, semen stored at $-196.5^{\circ} \mathrm{C}$ can retain enough fertilizing capacity to make pregnancy possible. Published reports document over 500 normal births resulting from the use of frozen semen. ${ }^{4}$ This paper reports some of the findings of a study undertaken to identify and evaluate the role of these banks in medical practice and the consequences which might ensue.

\section{Family Planning}

Perhaps the most frequent use of frozen semen is for "donor insemination" to enable infertile couples to have children. The use of a donor's semen is medically indicated in male sterility, rhesus incompatibility, when the husband is a carrier of a hereditary disease, and in most cases of oligospermia. One of the more important aspects of medical practice highlighted by the increase in frozen-semen banking is the role of the doctor in selecting couples for artificial insemination. Though that responsibility rests with the doctor little is known about how he makes his choice. There are no specific professional guidelines or legal codes to help him, though some experienced with the procedure would make artificial insemination available only to couples who have a stable marriage and are emotionally mature. But these criteria are open to a wide latitude of interpretation. Furthermore, Kleegman, who noted that "few physicians have the psychological training to accept this great responsibility," 5 raises the important question of how such decisions can be made in a more scientific and equitable manner.

The availability of frozen-semen banking as an integral part of family planning programmes also raises questions about the use of and requirements for informed consent. There are no standard procedures among semen cryobanks for obtaining informed consent. Some banks provide no consent forms at all. There are, however, compelling reasons for instituting appropriate consent procedures-for example, we still know little about the effects of frozen semen including its efficacy and genetic consequences. The American Public Health Association has recently warned that "the biologic potency and genetic adequacy of human sperm which has been frozen and stored over a protracted period of time and then thawed remains to be established." There is, however, neither evidence nor assurance that such a warning is ever communicated to prospective users. Finally, there is the question of who should request the consent. In the past the responsibility for obtaining valid consent rested with the doctor who performed the insemination. But does the emergence of semen banks shift this responsibility ? Should the request for consent come from the doctor who requested the use of the frozen semen and who may be required to share legal responsibility for its use or should it come from the semen bank, which has had the more direct contact with the donor?

\section{Substitute for Adoption}

One application of frozen-semen banking is to provide a more readily available and acceptable alternative to adoption for infertile couples. Studies have shown that most couples using artificial insemination prefer it to adoption. ${ }^{6}$ Of the many reasons for this probably artificial insemination more than adoption can satisfy a woman's psychological drive directed toward bearing children. Adoption, then, can never be regarded as a fully adequate substitute for maternity. This raises the question of what consideration is to be given to the welfare of the "hard-to-place" child, for whom it has been virtually impossible to find a home even without the additional competitive pressures exerted by an increase in demand for frozen-semen banking. Hence it may well not be in society's best interest to strive toward total fertility in married couples.

\section{Vasectomy "Insurance"}

There is a growing recognition of a relation between the interest in vasectomy, the storage of frozen semen, the growth of commercial frozen-semen banks, and population control. The possibility of future fertility through the freezing and storage of semen may encourage some men to undergo vasectomy. This use of frozen-semen banking has been challenged by the National Medical Committee of Planned Parenthood-World Population. Because of what it considers to be the highly experimental nature of semen cryobanking the committee has argued that "the promise of fertility insurance to be achieved by storing semen may be misleading. Moreover, it may lead to the persuasion of immature or poorly motivated individuals to undergo vasectomy." Since many men may use frozen-semen banking to try to overcome their anxiety over the irreversibility of vasectomy there is the danger that the promise that not all possibility of fatherhood is lost with a vasectomy will be used to take advantage of basic human emotions. Artificial insemination with frozen semen is not always successful and a man is deluding himself if he believes that he can deposit his semen, have it frozen, and then return a few years later and be certain of having children. All men (and their wives) must be fully informed, therefore, of the scientific knowledge regarding semen cryobanking as well as the procedures and possible consequences of vasectomy. Such information should include the caution that there is no "guarantee" that semen specimens will be usable at a later date.

\section{Fertility Research}

Many if not all semen banks are using stored semen for fertility research. This raises an immediate ethical question about the possible conflict of interest of a doctor involved in this research who at the same time counsels his patients on the therapeutic or contraceptive benefits of banking semen. For example, an over-ambitious investigator may, in promoting his research as well as his own scientific recognition, perform his responsibilities as a doctor without proper regard for his patient's interest. This problem is clearly emphasized by the warning that the promise of fertility insurance through the storage of semen may persuade some immature or poorly motivated patients to undergo vasectomy.

Those seeking to store their semen in a frozen-semen bank for whatever purpose must be told of the research for which their semen may be used and its possible consequences. It should be made clear that their semen will be used for no other research purpose without their written consent. While it may be relatively "harmless" as well as agreeable to the donor for his semen to be used in research on the motility of spermatozoa it is quite a different matter if his semen, in the name of scientific research and without his consent, is used to cause pregnancy by artificial insemination in a woman other than his wife. Yet only one of the three commercial banks has a storage agreement which prohibits explicitly the use of any specimen without the client's consent for causing pregnancy by artificial insemination. Furthermore, at least one bank has suggested that semen might be used for research relating to in-vitro fertilization. It is doubtful whether persons who contemplate banking their sperm are awarè of this possibility; present storage agreements and consent forms do little to increase their awareness. The question must be raised here, however, of the ethical propriety of using donor semen for experimentation relating to in-vitro fertilization without properly executed informed consent.

\section{Donor Selection and Compensation}

Sensitive issues regarding the role and responsibility of doctors emerge with the selection and compensation of semen donors. Among American semen banks donor selection is done by the doctor scheduled to perform the insemination. In the case of 
commercial banks the doctors will initiate the request for a donor from a "donor pool" which has been established by the bank. The methods for donor selection vary widely. Some banks will attempt to match the donor and recipient for their physical characteristics. Some require that the donor have a stable marriage and that he be of proved fertility; others, however, assign little importance to these criteria. Some banks perform screening tests and chromosome analyses for possible genetic defects; others rely on the more easily obtained medical and genetic history. Because of this variation in the standards and criteria for donor selection there is no uniform minimum standard of practice on which prospective parents and the community can rely.

A more stringent and uniform set of medical and genetic tests of prospective donors is urgently needed to minimize the risk of transmitting genetic or infectious diseases. Already the transmission of gonorrhoea by artificial insemination has been reported. ${ }^{7}$ Since the accuracy of a medical or genetic history depend heavily on the knowledge and truthfulness of the donor the semen bank which does not perform a medical follow-up necessarily relies on the donor's knowledge and on his willingness to impart this knowledge truthfully. A donor, however, may not know that he is a carrier of a transmittable disease; and reliance on the honesty of the donor also has its pitfalls. Thus procedures for screening and selecting donors remain the key factor in controlling the transmission of infectious and genetic diseases. In the absence of such procedures the subsequent biological condition of the recipients of the semen and of their offspring remains the ultimate test of the biological and genetic adequacy of the donated semen. To select semen donors without the proper medical and genetic follow-up tests suggests the taking of highly unethical risks from which the inseminated woman, her husband, and their potential child might suffer.

The compensation of semen donors also carries important consequences. Semen banks which store semen from donors rely primarily on paid donors. With an increase in commercial frozen-semen banks American medicine may witness an increasing commercialization of semen donation-which raises several questions about the long-term impact on social values. If semen is treated in practice as a commodity to be bought and sold what will be the impact on prospective donors of blood, eyes, or kidneys ? Will they also become just other "commodities" in the market-place? How will the entrance of semen banking into the market-place affect the sense of obligation incurred by donors? Will remuneration be viewed as a sign that they no longer need to be concerned with the consequences of their act?

As well as these long-term issues there are more immediate consequences for medical practice. For example, how likely is it that a donor with a drug habit, using drugs that may cause permanent chromosomal damage, will seek remuneration for his semen as a way of maintaining his habit? Syphilis and gonorrhoea are infectious diseases which can be deleterious to both the recipient and the fetus. As the commercialization of semen donation increases will those who have contracted either syphilis or gonorrhoea constitute a large proportion of paid semen donors? At present semen banks report that they rely primarily on medical students for donors. But whether this group will continue, under the pressures of commercialization, to be a readily available and desirable source in the future remains to be seen.

\section{Prospective Uses}

In addition to the role which semen cryobanking now assumes in medical practice it has the potential for having a broader and more socially oriented role in the future. For example, it might be used as a method for helping couples choose the sex of their children or for influencing the genetic quality of the species by making available a wide range of genetic material (as found in frozen semen) for selection independent of time. But should semen cryobanking be used for these socially desired purposes? An important issue that this raises concerns the ethical propriety of distributing non-essential but highly valued medical resources. The application of semen-bank technology to social purposes portends clear biological and social consequences for more of the population than a single couple and their offspring. The responsibility for selecting suitable candidates will therefore become a social as well as a medical decision. A critical policy question, then, will be whether doctors should retain their sole responsibility for such decision making, or rather, should the decision making domain be enlarged to include other sectors of society which may more accurately reflect the community's social mores?

\section{References}

1 Mantegazza, P., Reniconti Reale Instituto Lombardo, 1866, 3, 183.

2 Smith, K. D., and Steinberger, E., Fournal of the American Medical Association, 1973, 223, 774.

${ }^{3}$ Behrman, S. J., and Ackerman, D. R., American fournal of Obstetrics and Gynecology, 1969, 103, 654 .

4 Sherman, J. K., Fertility and Sterility, 1973, 24, 397.

5 Kleegman, Sophia J., In Advances in Sex Research, ed. H. G. Beigel, p. 118. New York, Harper and Row, 1963 .

p. 118. New York, Harper and Row, 1963.
${ }^{6}$ Lovset, J., Fertility and Sterility, 1951, 2, 415.

7 Fiumara, N. J., British fournal of Venereal Diseases, 1972, 48, 308.

\section{Any Questions?}

\section{Hazards of Embalmers}

What are the occupational hazards of being an embalmer, or an embalmer's wife?

Dangers to embalmers may arise from two general causes: the effects of the embalming fluid and the possibility of infection from the corpse. An embalmer may rarely be exposed to radiation from patients who have been treated with radioactive isotopes, but this is only likely to be significant in hospital patients, in which case proper precautions would be taken. The main noxious substance in embalming fluid is formalin, which can cause dermatitis (and this may be severe and resistant to treatment), bronchospasm, bronchitis, and possibly more serious pulmonary damage in some patients. Hypersensitivity to formaldehyde may occur for the first time even after years of handling formalin.

The embalmer is not likely to be infected by the corpse because embalming is seldom associated with much blood spillage and most embalmers wear gloves and other protective clothing. Some hazards, however, such as tuberculosis and hepatitis must exist. The British Institute of Embalmers is aware of the dangers and has issued a notice to its members on this topic. It is difficult to envisage any hazard to an embalmer's wife, except for the remote possibility of transmitted infection. 